\title{
PENCEGAHAN DAN PENATALAKSANAAN TERKINI PENYAKIT TRAVELERS DIARRHEA UNTUK WISATAWAN YANG BERKUNJUNG KE INDONESIA
}

\author{
${ }^{1}$ Sarayar, A. M., dan ${ }^{1}$ Liwang, F. \\ ${ }^{1}$ Fakultas Kedokteran Universitas Sam Ratulangi Manado \\ (hardy_sarayar@yahoo.com)
}

\begin{abstract}
ABSTRAK
Dari jutaan orang yang melakukan perjalanan dari dunia industri ke negara-negara berkembang setiap tahun, sekitar $20 \%$ dan $50 \%$ akan mengalami setidaknya satu episode diare sehingga traveler's diarrhea menjadi penyakit medis yang paling umum menimpa wisatawan. Meskipun biasanya digolongkan penyakit ringan, diare dapat menyebabkan morbiditas yang signifikan dan kesulitan ketika kita berada di luar negeri. Tindakan pencegahan dapat diambil untuk meminimalkan risiko mengembangkan diare, baik melalui penghindaran makanan berpotensi atau minuman yang tercemar atau melalui berbagai langkah-langkah pencegahan, termasuk strategi baik dengan antimotilitas dan antimikroba. Jika diare tetap terjadi meskipun tindakan pencegahan telah diambil, pengobatan yang biasanya diberikan adalah kombinasi dari antibiotik dan agen antimotilitas. Pengetahuan yang memadai sesuai perkembangan pengetahuan yang ada diperlukan agar pengobatan yang diberikan dapat efektif. Sekarang ini beberapa vaksin sudah berada dalam tahap lanjutan untuk dimasukan sebagai tindakan profilaksis.
\end{abstract}

Kata kunci: traveler's diarrhea, pencegahan, penatalaksanaan, antimotilitas, antimikroba, vaksin

\section{DEFINISI}

- Diare adalah buang air besar (defekasi) dengan tinja berbentuk cair atau setengah cair (setengah padat), kandungan air tinja lebih banyak dari biasanya lebih dari 200 gram atau $200 \mathrm{ml} / 24 \mathrm{jam}$.

- Dari sudut pandang frekuensi, dikatgorikan diare jika sudah buang air besar encer lebih dari 3 kali per hari. Buang air besar tersebut dapat disertai lendir dan darah.

- Traveler's diarrhea (TD) adalah diare yang dialami oleh wisatawan akibat terpapar patogen di daerah tujuannya.

\section{EPIDEMIOLOGI}

- $\quad$ Tempat tujuan merupakan faktor risiko paling menonjol dalam berkembangnya kasus TD. Daerah yang berisiko tinggi di antaranya negaranegara berkembang di Amerika Latin, Afrika, Asia, dan sebagian Timur Tengah. Di daerahdaerah tersebut telah dilaporkan memiliki angka serangan berkisar 20 sampai $75 \%{ }^{3}$ Wilayah dengan risiko menengah termasuk Cina, Eropa Selatan, Israel, Afrika Selatan, Rusia, dan beberapa Pulau Karibia (khususnya Haiti dan Republik Dominika); serangan dengan kisaran $8 \%$ sampai $20 \%$ tercatat pada pelancong ke daerah ini. Kanada, Amerika Serikat, Australia, New Zealand, Jepang, Eropa Utara, dan sedikit pulau-pulau di Karibia memiliki faktor risiko rendah, yaitu berkisar $<5 \%$. Indonesia termasuk di negara dengan tingkat serangan diare turis yang tinggi.

- Musim juga turut berperan dengan angka kejadian TD. Penelitian yang telah dilakukan di daerah yang memiliki empat musim mendapatkan serangan paling sering ditemukan pada bulan-bulan di musim panas dan musim hujan.

- Konsumsi makanan dan minuman yang tercemar merupakan sarana masuk dari sebagian besar kuman penyebab diare sehingga risiko bervariasi sesuai dengan perhatian yang diberikan terhadap diet.

\section{ETIOLOGI}

Penyebab utama dari sebuah studi di RS Persahabatan Jakarta berurut dari yang paling sering

1. E.coli, terutama strain ETEC, EAEC, dan DAEC

2. Vibrio cholera Ogawa

3. Aeromonas sp

4. Shigella flexneri

5. Salmonella $\mathrm{sp}$

6. Entamoeba histolytica 
7. Ascaris lumbricoides

8. Rotavirus

9. Candida sp

10. Vibrio NAG

11. Trichuris trichiura

12. Plesiomonas shigelloides

13. Ancylostoma duodenalis

14. Blastocystis hominis

Ket: $\quad$ ETEC $=$ Enterotoxigenic $E$. coli $\mathrm{EAEC}=$ Enteroaggregative $\mathrm{E}$. coli DAEC $=$ Diffusely adherent $E$. coli

\section{FAKTOR RISIKO}

Beberapa faktor risiko telah diidentifikasi berhubungan erat dengan berkembangnya traveler's diarrhea. Faktor-faktor risiko tersebut kita pisahkan antara yang bisa dikontrol dengan yang tidak bisa dikontrol.

- Faktor-faktor risiko yang bisa dikontrol:

1. Tingkat kebersihan dari negara asal dan tujuan adalah hal yang mendasar dalam berkembangnya diare turis.

2. Usia turis, insiden tertinggi termasuk anak-anak kecil dan orang dewasa muda berusia 21 sampai 29 tahun. Balita yang sering menempatkan benda-benda di mulut merekaenunjukkan tingkat kejadian diare yang tinggi, seperti halnya remaja, yang biasanya memiliki selera makan yang besar.

3. Olahraga yang sesuai dengan apa yang dimakan dapat melindungi individu terhadap TD

4. Jenis perjalanan, individu yang tinggal dengan penduduk setempat, backpacking, berkemah, yang melakukan perjalanan hiking dilaporkan lebih sering menderita diare.

5. Makanan yang disajikan di rumah pribadi memiliki risiko yang lebih rendah daripada yang ada di restoran. Membeli makanan atau minuman dari Pedagang Kaki Lima (PKL) dilaporkan sangat riskan menimbulkan diare.

- Beberapa faktor risiko pejamu tidak dapat diubah oleh perilaku:
Faktor genetik membantu menjelaskan mengapa dalam 1 anggota keluarga, ada yang menjadi sakit sementara yang lain tidak meskipun risiko lingkungan sama. Penelitian yang dilakukan telah menunjukkan bahwa single nucleotide polymorphisms (SNP) telah dikaitkan dengan peningkatan risiko TD atau diare karena patogen TD tertentu.

1. Polimorfisme genetik dalam grup antigen histo-blood, seperti penggolongan darah $\mathrm{ABO}$, secretor status, dan kehadiran antigen Lewis, berhubungan dengan kerentanan tinggi terhadap infeksi oleh strain norovirus.

2. Orang dengan golongan darah $\mathrm{O}$ memiliki peningkatan risiko timbulnya gejala berat ketika terinfeksi Vibrio cholera.

3. Kehadiran SNP tertentu pada pejamu dalam gen penanda inflamasi telah dikaitkan dengan kerentanan yang lebih tinggi menderita traveler's diarrhea, termasuk IL-8 (salah 1 leukosit prekursor polimorfonuklear), IL-10 (suatu sitokin anti-inflamasi), laktoferin (komponen granula netrofil), dan osteoprotegerin (anggota dari superfamili reseptor tumor necrosis factor).

\section{GEJALA KLINIS}

Diare biasanya didefinisikan sebagai bagian dari setidaknya tiga kali buang air besar berbentuk dalam jangka waktu 24 jam, dalam hubungan dengan setidaknya satu gejala dari penyakit pencernaan seperti mual, muntah, demam, perut atau kram, tenesmus, urgensi tinja, atau bagian dari tinja berdarah atau berlendir. Biasanya, gejala berkembang dalam minggu pertama perjalanan dan lebih dari $90 \%$ kasus terjadi dalam 2 minggu pertama. Sekitar $80 \%$ dari wisatawan dengan diare mengeluh kram perut, $10 \%$ sampai $25 \%$ mengalami demam, 20\% mengalami muntah, dan antara 5\% dan $10 \%$ melaporkan memiliki darah atau lendir dalam tinja mereka. Pada kebanyakan kasus, diare biasanya hanya berlangsung selama 3 sampai 4 hari sebelum sembuh secara spontan tanpa pengobatan. 


\section{KOMPLIKASI}

- Dehidrasi dapat timbul jika diare dan asupan oral terbatas karena nausea dan muntah, terutama pada anak kecil dan lanjut usia. Dehidrasi bermanifestasi sebagai rasa haus yang meningkat, berkurangnya jumlah buang air kecil dengan warna urine gelap, tidak mampu berkeringat, dan perubahan ortostatik. Pada keadaan berat diare dapat mengarah ke gagal ginjal akut. Dehidrasi menurut keadaan klinisnya dapat dibagi atas 3 tingkatan:

- Dehidrasi Ringan (hilang cairan 2-5\% BB): gambaran klinisnya turgor kurang, suara serak (vox cholerica), pasien belum jatuh dalam presyok.

- Dehidrasi sedang (hilang cairan 5-8\% BB): turgor buruk, suara serak, pasien jatuh dalam presyok atau syok, nadi cepat, napas cepat dan dalam.

- Dehidrasi berat (hilang cairan $8-10 \%$ BB): tanda dehidrasi sedang ditambah kesadaran menurun (apatis sampai koma), otot-otot kaku, sianosis.

- Komplikasi juga dapat terjadi setelah kembali ke negara asal turis. Pasien dengan TD dapat terus mengeluh rangkaian gejala gastrointestinal persisten atau intermiten, termasuk diare, sembelit, sakit perut, atau bloating (kembung). Antara 5\% sampai $10 \%$ dari wisatawan dengan TD biasanya di kemudian hari akan memenuhi kriteria Roma II untuk irritable bowel syndrome (IBS). Ketika IBS dimulai setelah serangan diskrit diare atau gastroenteritis, ini disebut sebagai postinfectious (PI)-IBS. Dalam sebuah klinik untuk penderita IBS di AS, sekitar $10 \%$ pasien telah melakukan perjalanan internasional 6 bulan sebelum muncul gejala IBS. Hal ini menunjukkan kemungkinan adanya ketertarikan antara TD dan berkembangnya PI-IBS.

\section{PENCEGAHAN}

- Minuman di tempat tujuan sangat berperan penting. Turis disarankan untuk mengonsumsi hanya minuman yang "aman", seperti yang telah direbus, di dalam botol, atau minuman berkarbonasi. Di daerah di mana air keran tidak diklorinasi atau memiliki sanitasi yang buruk, ada beberapa metode alternatif untuk mengolah air agar aman untuk diminum, seperti pendidihan air, filtrasi, desinfeksi dengan bahan kimia (Halogen, Resin lodin, Elektrolisis dengan Garam [Sodium Klorida], atau Klorin dioksida), penggunaan sinar ultraviolet, penggunaan dengan pemanasan dengan sinar matahari, penggunaan perak dengan beberapa produk lainnya. Teknik yang optimal bagi seseorang atau kelompok tergantung pada preferensi pribadi, ukuran kelompok, sumber air, dan tipe perjalanan. Pemanasan adalah pengobatan tunggal dan langkah yang paling dapat diandalkan, tetapi filter tertentu, UV, dan klor dioksida juga efektif dalam sebagian besar situasi. Pengobatan yang optimal dari air yang sangat tercemar atau berawan mungkin memerlukan CF diikuti oleh disinfeksi kimia.

- Makanan seperti buah, termasuk tomat, harus dikupas, kecuali telah dicuci bersih dalam air yang "aman". Usahakan mengupas sendiri buahbuahan sebelum dikonsumsi. Salad dan sayuran mentah harus dihindari. Untuk daging atau ikan, hanya yang sudah dimasak dengan benar dan baru saja yang boleh dimakan. Sisa makanan dan bumbu dalam wadah terbuka serta makanan dari PKL telah secara konsisten telah terbukti membawa peningkatan risiko.

- Pemilihan nonantibiotik yang dinilai paling efektif diantaranya adalah Bismuth subsalicylate(BSS; Pepto-Bismol) yang telah terbukti memiliki aktivitas antimikroba ringan serta antisekresi dan antiinflamasi. Namun, perlu ditinjau efek samping, kontraindikasi jika sedang menggunakan obat tertentu, dan syarat penggunaannya.

- Beberapa antibiotik, seperti berbagai Fluorokuinolon dan rifaxmin telah terbukti sangat efektif dalam pencegahan diare. Namun, profilaksis antibiotik boleh diberikan hanya dalam penggunaan singkat dan hanya saat keadaan khusus.

- Pemakaian kemoprofilaksis tetap harus jangka pendek (kurang dari 3 minggu) untuk sejumlah alasan, seperti antibiotik profilaksis menimbulkan rasa aman palsu bagi pelancong, berkembangnya patogen yang resisten terhadap antibiotik, reaksi berat seperti sindrom StevensJohnson atau anafilaksis, dan lain-lain.

- Vaksin oral dari strain ETEC yang dilemahkan sedang dalam pengembangan dan telah terbukti immunogenik. Namun, penelitian lebih lanjut 
diperlukan dalam pengembangan vaksin TD untuk menilai kemampuan vaksin ini dalam pencegahan penyakit.

\section{PENATALAKSANAAN}

- Dehidrasi adalah masalah utama bagi penderita diare. Oleh karena itu, penanganan rehidrasi sangat penting bagi pasien. Sebelum memberikan rehidrasi, perlu dinilai dulu derajat dehidrasi yang terdiri dari ringan, sedang, dan berat. Prinsip menentukan jumlah cairan yang akan diberikan yaitu sesuai dengan jumlah cairan yang keluar dari tubuh. Ada bermacammacam cara pemberian cairan, seperti dengan rumus BJ plasma, metode Pierce berdasarkan klinis, dan metode Daldyono.

- Untuk diet, Selama fase akut penyakit, pasien disarankan minum minuman sari buah, teh, dan minuman tidak bergas. Dianjurkan memilih makanan yang terdiri dari karbohidrat kompleks seperti nasi, roti, kentang, pisang, dan biskuit. Minuman berkafein dan beralkohol harus dihindari karena dapat meningkatkan motilitas dan sekresi usus. Susu sapi harus dihindari karena ada defisiensi laktase yang transien.

- Agen antimotilitas utama untuk mengatasi gejala diare adalah Loperamide (Imodium). BSS merupakan pilihan antidiare nonantibiotik yang memiliki efek antisekresi, antiinflamasi, dan sifat antimikroba dan yang mengurangi frekuensi defekasi dan durasi diare sekitar 50\%. Namun, BSS kurang efektif jika dibandingkan dengan loperamide. Pemakian antimotilitas harus hatihati jika ada tanda-tanda disentri sebagaimana diperlihatkan dengan gejala seperti demam tinggi atau diare berdarah karena kemungkinan mereka dapat menunda pembersihan enteropatogen invasif sehingga memperpanjang perjalanan penyakit.

- Pengobatan dengan antibiotik dianjurkan terhadap semua kasus TD sedang sampai berat dengan nyeri perut, kram, atau diare, terutama jika ada demam atau gejala disentri.Sampai saat ini, 3 antibiotik telah ditemukan efektif untuk memperpendek durasi TD. Obat yang direkomendasikan ini termasuk fluorokuinolon (siprofloksasin atau levofloksasin), rifaximin (Xifaxan, Salix), dan azitromisin.

\section{SIMPULAN}

Dari hasil pembahasan, bisa disimpulkan bahwa traveler's diarrhea masih merupakan penyakit yang sangat merugikan bagi wisatawan maupun negara tempat tujuan wisata. Pencegahan dan penatalaksanaan penyakit ini terus berkembang seiring dengan penelitian yang dilakukan. Diperlukan pengetahuan yang benar dan aktual bagi para wisatawan, dokter maupun masyarakat agar dapat menurunkan angka kejadian penyakit ini.

\section{SARAN}

Dokter dan wisatawan yang ada di Indonesia perlu banyak mencari informasi dan menerapkannya agar dapat menangani masalah diare turis ini dengan efektif. Masyarakan dan pemerintah juga perlu turut berperan serta agar tercipta lingkungan yang lebih higenis.

\section{DAFTAR PUSTAKA}

1. Anonim, 2004. Archieved Highlight: New Drug Approved for the Treatment of Travelers' Diarrhea, http://wwwnc.cdc.gov/travel/page/diarrhe a-drug-approved.htm diakses tanggal 23 Desember 2011

2. Anonim, 2007. Diseases Related to Travel, http://wwwnc.cdc.gov/travel/page/disease s.htm diakses tanggal 22 Desember 2011.

3. Anonim, 2006. Travelers' Diarrhea, http://www.cdc.gov/ncidod/dbmd/diseasei nfo/travelersdiarrhea g.htm diakses tanggal 22 Desember 2011.

4. Anonim, 2006. Water Treatment Methods, http://wwwnc.cdc.gov/travel/page/watertreatment.htm diakses tanggal 27 Desember 2011.

5. Backer H. D., 2011. Water Desinfection for Travelers,

http://wwwnc.cdc.gov/travel/yellowbook/2 012/chapter-2-the-pre-travelconsultation/water-disinfection-fortravelers.htm diakses tanggal 27 Desember 2011.

6. Badan Pusat Statistik. Jumlah Wisatawan Mancanegara ke Indonesia Menurut Negara Tempat Tinggal 2005-2010. Jakarta: BPS, 2009.

7. Bauche J. D. L. C., 2011. New Developments in Traveler's Diarrhea, 
http://www.ncbi.nlm.nih.gov/pmc/articles/ PMC3061023/ diakses tanggal 20 Desember 2011.

8. Bisnis Indonesia Intelligent Unit, 2012. DATA TURIS: Jumlah Wisatawan Mancanegara 6,93 Juta Januari-November 2011, http://www.bisnis.com/articles/dataturis-jumlah-wisatawan-mancanegara-6-93juta-januari-november-2011 diakses tanggal 5 Januari 2012.

9. Blahd, W. H., Jr., M. D., O'Connor H. M., M. D., 2010. Diarrhea Age 11 and Younger, http://www.health.com/health/library/topi c/0, diar3 hw86963,00.html diakses tanggal 21 Desember 2011.

10. -----, 2010. Traveler's Diarrhea, http://www.health.com/health/library/mdp 10, aa140669,00.html\#aa140669-sec diakses taggal 22 Desember 2011.

11. Diemert D. J., 2006, Prevention and SelfTreatment of Traveler's Diarrhea, http://www.ncbi.nlm.nih.gov/pmc/articles/ PMC1539099/?tool=pubmed diakses tanggal 20 Desember 2011.

12. Gobarch, S. L, 1990. Bismuth Therapy in Gastrointestinal Diseases, http://www.ncbi.nlm.nih.gov/pubmed/219 9292 diakses tanggal 23 Desember 2011.

13. Green, W. M., M. D., Colby, W. D. IV, MSc, M. D., FRCPC, 2010. Travel Health, http://www.health.com/health/library/topi c/0, te7636 te 7637,00.html diakses tanggal 20 Desember 2011.

14. Sudoyo, Aru W., dkk. Buku Ajar Ilmu Penyakit Dalam .Ed. Ke-5. Dalam: K., Simadibrata, Daliyono. Diare Akut. Jakarta: InternaPublishing, 2009: 548-555.

15. Syarif, Amir, dkk. Farmakologi dan Terapi. Ed. ke-5. Jakarta: Departemen Farmakologi dan Terapeutik Fakultas Kedokteran Universitas Indonesia, 2009: 718-722.

16. Weinberg N., Weinberg M., Maloney S. A., 2011. Traveling Safely With Infants and Children,

http://wwwnc.cdc.gov/travel/vellowbook/2 012/chapter-7-international-travel-infantschildren/traveling-safely-with-infants-andchildren.htm diakses tanggal 26 Desember 2011. 